\title{
Imagining Coastal Change: Reflections on Making a Film
}

\section{Stephen Daniels and Lucy Veale}

\section{University of Nottingham, UK}

\section{Introduction}

\section{Figure 1}

This photograph (Figure 1) shows preparations for the opening and closing sequences of Imagining Change: Coastal Conversations, a short film we made at short notice, during the first three months of $2012 .{ }^{1}$ Taken by Lucy Veale, who documented the filmmaking, the photograph shows the film's presenter Stephen Daniels, learning lines we had just scribbled down inside the shelter of the film crew's vehicle, before heading out on location on the Suffolk coast, on a sub zero February day. The other figures, from the creative agency Nice and Serious, are sound recorder Tom Tapper, camera operator Matt Harmer, and to the right the Director Ben Meaker who had, in these conditions, mercifully relaxed the dress code rules for presenters and allowed Stephen to wear hat and gloves on screen.

In this article we will discuss some issues arising from the making of the film as a medium and method for showing, and showcasing for a wide audience, the different 
forms of arts and humanities practice - narrating, performing, picturing - the film features in relation to environmental change.

\section{The Film}

The film was commissioned by the Arts and Humanities Research Council (AHRC) for the international conference 'Planet under Pressure', held 26-29 March 2012, as part of AHRC's contribution to the Research Councils United Kingdom (RCUK), multi-agency, Living with Environmental Change programme. ${ }^{2}$ The film was also incorporated into the Impact Fellowship awarded to the AHRC's strategic programme in Landscape and Environment.

The intention was to demonstrate the value of incorporating arts and humanities approaches into research on environmental change, in formulating new questions and generating new answers. The film focuses on different narratives of environmental change, ${ }^{3}$ using a range of stories at different scales and tempos and featuring historical continuities as well as change. This narrative range is made possible, certainly in the UK context, by the recent loss of the compelling power of the term 'Climate Change.' In many arenas climate change has now lost its capital letters and certainly a degree of its original impact, replaced by a more measured approach. Concerted campaigns against the term are evident - one symptom of which was the 
recent attempt to removed climate change from the National Curriculum for geography lessons.

One of the programme partners, National Trust, recommended Nice and Serious (company motto 'Serious Issues, Nicely Visualised'). ${ }^{4}$ An 'environmental and ethical film production company' based in London, they were able to work quickly to our tight timeframe, and, no less importantly, to our budget. After various exchanges, we agreed to their proposal for the film in December 2011. The major communication issue for us, and initially a difficult one with a studio with expertise in environmental science and sustainability, was to establish an arts and humanities message. ${ }^{5}$ This they found "hard to get their heads around" until we started initial scripting, which, rather like writing art exhibition captions and catalogue entries is an exercise in succinct plain speaking with strict limits on length and vocabulary, if not stinting on technical terms. Indeed the studio enthusiastically embraced the new opportunities offered by the approach. Fieldwork matters for cultural geography at large, bringing arcane sounding theoretical and methodological questions down to earth, as does personalising these issues in conversation.

\section{Coastal Conversations}


As a popular location and trope in recent arts and humanities research and scholarship, and books and television films for a wider public, the coast was chosen as the framing landscape type for the film. We were wary of the established example of the popular BBC programme Coast, which had become almost a parody of itself, with the figure of the windswept anoraked presenter marching along a cliff top bellowing out facts and figures, cutting away to helicopter panoramas. We didn't have the budget for helicopters, but the wintry weather of the filming week helped to create the visuals of a seriously coastal field project.

We decided to structure the film through a sequence of encounters with researchers at sites of projects addressing environmental change: Mullion Cove in Cornwall, the Lincolnshire side of the Humber estuary at Alkborough, and the Deben estuary in Suffolk. The order of appearance followed the sequence of filming, if little else in the film is chronological or in real time.

At each location the presenter set the scene, walking to the location, with wide-angle landscape shots, followed by a to and fro conversation staged between the presenter and researcher. This strong human presence is a signature style for Nice and Serious. So a film about landscape, conveying what we talk about when we talk about landscape, is communicated by a focus on figures, on expressive face, hands, gesture 
and voice. The close ups of locations - of water running over rock, of paint on boats and canvas, as well as the mobile skin of presenters as they spoke, emphasises a material world, with intimate surfaces at a series of interfaces.

Imagining Change was filmed using two Canon 5D mark 2 digital SLR cameras with prime lenses. These use a full frame sensor and constant aperture, letting in more light and thus capturing richer images and generating a more 'filmic' look. Audio was recorded using a 4-channel mixer with radio microphones and a boom.

Filming took place at the beginning of February, so the team had to work quickly, in widely spread locations, in a month of limited daylight hours with often low light levels. There were three and a half days of actual filming, and over a thousand miles travelled. In the first encounter at Mullion Harbour, Cornwall, a highly problematic site for landscape protection, telling was showing. Recent studies of environmental change at this popular tourist spot (and home of a small fishing community) have shown that storm damage to the Harbour structure is likely to increase, with over $f 1$ million spent on maintenance and repair in recent years. The result has been that a basic costbenefit exercise has become part of a more philosophical inquiry. Technical terms are an important part of the conversation with Caitlin DeSilvey: 'experimental narration', 'reverse chronology', 'anticipatory history' and 'palliative curation'. These terms had 
already been already road tested with National Trust, to address and communicate the decision to adopt a policy of managed retreat for the storm battered structure it owns. ${ }^{6}$ So what might have been too loosely framed as 'story telling' we hope arrests the attention of environmental scientists and policy makers with their own technical vocabulary, as well as raising the communicative issue of appropriate languages for landscape, and the terminology for expressing environmental change. ${ }^{7}$ In postproduction we edited in a number of $19^{\text {th }}$ and $20^{\text {th }}$ century photographs over location shots to make the point about how historically recent the timeless looking Mullion Harbour is (built between 1893 and 1895), and how coastal change and ruination might be managed, along with the National Trust motto 'Forever for Everyone'.

\section{Figure 2}

The second site proved challenging for it was so un-picturesque (Figure 2). The snow gave definition to a relatively flat, featureless stretch of intertidal mudflats, if it did infill and obliterate the turf maze we had been planning to use as a stage device. The landscape in question surrounds one of the largest flood storage schemes in Europe, where a new wetland has been created. We had already commissioned a performance work by Mike Pearson on the longer history of building up and letting go of the land at Alkborough, titled Warplands, named after the reclamation technique of warping. In 
the edit suite we experimented with inserting sections of the audio recording of Warplands, foregrounding the conversation with Mike, as he pointed out features in the panorama, or walked the embankment next to the mudflats. This technique of insertion was effective as Mike, an accomplished theatre actor and director, had a strongly performative style, with strong physical and vocal eloquence, thereby highlighting the performative aspect of this presentation and, by extension, that of the others. ${ }^{8}$

In the third location we were able to show practice in situ, the conversation filmed in the sea-going barge that serves artist Simon Read as his home and studio. Simon has made a series of drawn and painted mapworks to re-examine stated flood risk management policy, and he talked this through in relation to work in progress. Simon's mapworks are collected under the title Imagining Change which we decided to use for the main title of our film, and his interview also provided the subtitle, for he emphasised the role of these maps in stimulating conversations amongst many kinds of people about present change and future scenarios. ' 'Conversation' as a wider term, embracing conversations between disciplines, and between various publics, emerged as a framing theme of the film.

\section{Figure 3}


The location for the opening and closing of the film is East Lane Bawdsey on the Suffolk coast, the site of severe cliff erosion and some very hard engineered, concrete and rock armour defences. Designated as a Site of Special Scientific Interest (SSSI), the main landmark is a Martello tower, part of another, older defence system built to repel a Napoleonic Invasion. Here is a coast whose cultural profile has been raised as its physical profile has collapsed and receded.

A fortnight after filming we were in the edit suite to view the 23 minute 'rough content cut' sequence that had been put together using 'Final Cut Pro' editing software by Editor Nick Earp. We were listening rather than watching, to the conversational narrative of the film, cutting and rearranging, replacing or discarding footage. When we left we had reduced the cut to 16 minutes, which we circulated to our contributors. All raised concerns, mainly relating to coherence. Stylistically the film was edited to frame the story; as a reflective, almost meditative work, shots remains on screen for fractionally longer than it would usually.

The visual cut moved things along greatly: all camera angles were used, cutaway shots inserted and music from a stock library added. ${ }^{10}$ The film was then subject to colour grading (a flat palette reflecting the weather conditions), and the credits and 'lowerthirds' (names and titles) were added in. The final stage was encoding the film and 
producing a variety of file formats to screen at the Conference and to subsequently upload to the website.

All this does not come cheap. In an age of low cost amateur digital film making, we went for a highly professional product, with not much change from $£ 25,000 .^{11}$ It seems a lot, but not compared with costs of book and journal publishing, and of course the time frame from proposal to public release was so much shorter than most academic work.

\section{Screening and afterlife}

The premier screening took place on the evening of 27 March 2012. As discussant Mike Hulme (Professor of Climate Change at the University of East Anglia) explained, the film, through its demonstration of engagements with particular landscapes, illustrates how a narrative of a 'Planet under Pressure' emerges at particular places and touches local communities. "To shed new light on the multiple meanings of climate change in diverse cultures, and to create new entry points for policy innovation, the interpretative social sciences, arts and humanities need new spaces for meeting as equals with the positivist sciences" ${ }^{12}$ We hope our film is one such meeting space.

Online audiences have far exceeded conference delegates. We have been told about its use at a number of different events and settings including undergraduate and 
postgraduate teaching, public lectures, open days, National Trust workshops, conferences and seminars. It was shortlisted for the International Visual Communications Association (IVCA) Clarion Awards, recognised as premier marks of excellence for communications in video, interactive projects, business television and digital media. Simon Read has subsequently taken the project in a new direction through a Landscape and Environment Programme commission to produce a new map-work on the Alkborough Flats realignment scheme (Figure 4). Displayed on the route to the Map Library in the University of Nottingham's School of Geography this work was formally launched with an event on 'Lincolnshire Landscapes' in April 2013.

Figure 4

\section{Geography and Film}

Geography has a long, if episodic, relationship with film and filmmaking. This is changing from moving image interpretation, to a more practical sense of film making including some involvement in making films. ${ }^{13}$ In this essay we have documented our experiences of making a short film about a particular type of place, in collaboration with a creative studio. We have reflected on the medium as part of a larger field of multi-media practice and enquiry, including various forms of text and picture making, 
and some traditional geographical methods like map making and field walking and talking.

\section{Acknowledgements}

We would like to thank our contributors Caitlin DeSilvey, Mike Pearson and Simon Read and the Nice and Serious team for their work on the film and for comments on an earlier draft of this essay.

\section{Funding}

The film was commissioned by AHRC as part of AHRC's contribution to the RCUK, multi-agency, Living with Environmental Change programme.

\section{Notes}

${ }^{1}$ The film can be viewed and downloaded from:

www.landscape.ac.uk/landscape/impactfellowship/imaginingchange/planetunderpressure.aspx [Accessed March 2013]. The authors encourage wide dissemination of the resource.

${ }^{2}$ For more information on both see www.lwec.org.uk and www.planetunderpressure2012.net [Accessed March 2013].

${ }^{3}$ See S. Daniels, and G.H. Endfield, 'Narratives of climate change: introduction', Journal of Historical Geography 35 (2009), pp.215-222. 
${ }^{4}$ www.niceandserious.com [Accessed March 2013].

${ }^{5}$ Co-founders and directors Ben Meaker and Tom Tapper both have degrees in Environmental Science from UEA and masters degrees in Science Communication from Imperial College London.

${ }^{6}$ C. DeSilvey, 'Making sense of transience: an anticipatory history', cultural geographies 19 (2012), pp.30-53. National Trust took ownership of the site in 1945.

${ }^{7}$ C. DeSilvey, S. Naylor, and C. Sackett, Anticipatory History (Axminster, Uniformbooks, 2011).

${ }^{8}$ M. Pearson, 'Deserted places, remote voices: performing landscape', in S. Daniels, D. DeLyser, and J.N. Entrikin, eds., Envisioning Landscapes: Geography and the Humanities (Abingdon and New York, Routledge, 2011), pp. 280-286; M. Pearson, 'Warplands: Alkborough', Performance Research, Special Issue: On Foot 17 (2012), pp. 87-95; D. Matless and M. Pearson, 'A regional conversation', cultural geographies 19 (2012), pp. 123-9.

${ }^{9}$ Simon's Imagining Change series can be viewed on his website: www.simonread.info/imagining-change/ [Accessed March 2013].

${ }^{10}$ Music came from 'Audio Networks' (a stock library to which Nice and Serious pay an annual licensing fee). A process of trial and error selected the final soundtrack. A 
composer was of course another option but one too costly and time consuming for our brief.

${ }^{11}$ Inclusive of all expenses of all those involved.

${ }^{12}$ M. Hulme, 'Meet the humanities', Nature Climate Change, 1 (2011), pp. 177-9, p.179.

${ }^{13}$ S.C. Aitken and D.P. Dixon, 'Imagining geographies of film', Erdkunde 60 (2006), pp.326-36; M. Anton, B.L. Garrett, A. Hess, E. Miles, and T. Moreau, 'London's Olympic waterscape: capturing transition', International Journal of Heritage Studies (2012), pp.1-14; K. Brickell, and B. Garrett, 'Geography, film and exploration: women and amateur filmmaking the Himalayas', Transactions of the Institute of British Geographers, 38 (2013), pp.7-11; R. Craggs, "The long and dusty road': Comex travel cultures and Commonwealth citizenship on the Asian Highway', cultural geographies 18 (2011), pp. 363-83; Gandy, 'Liquid city'; B. Garrett, Session outline for 'Moving Geographies', RGS-IBG Annual Conference 2011; C. McGeachan, '(Re)remembering and narrating the childhood city of R.D. Laing' cultural geographies, published online before print, October 25 2012; H. Parr, 'Collaborative film-making as process, method and text in mental health research', cultural geographies 14 (2007), p.114-38. 